\title{
Research on Multi-Level Parking Solutions in Ho Chi Minh City
}

\author{
Vo Trong Cang ${ }^{1}$, Vo Minh Phuc ${ }^{2}$ \\ ${ }^{1}$ Faculty of Transportation Engineering, Ho Chi Minh City University of Technology, Ho Chi Minh City, Viet Nam \\ ${ }^{2}$ Sustainable Urban Development Program, Vietnamese German University, Binh Duong, Viet Nam
}

Email address:

votrongcang@gmail.com (Vo T. Cang),vominh.phuc95@gmail.com (Vo M. Phuc)

\section{To cite this article:}

Vo Trong Cang, Vo Minh Phuc. Research on Multi-Level Parking Solutions in Ho Chi Minh City. American Journal of Engineering and Technology Management. Vol. 5, No. 3, 2020, pp. 56-60. doi: 10.11648/j.ajetm.20200503.12

Received: February 25, 2020; Accepted: June 15, 2020; Published: July 4, 2020

\begin{abstract}
Parking or facilities serving people's parking needs play a very important role in the planning and development of the road transport system, which have an important influence on the sustainable urban development objective of Ho Chi Minh City (HCMC). However, after many different efforts and solutions, the problem of solving parking demand in HCMC area has not been completely solved, the reason comes from many objective factors and especially vacant land fund for the infrastructure is very limited. Understanding the reasons leading to the failure of the applied solutions, the study focused on the proposal, synthesizing parking models with small and medium scale, with appropriate technical specifications. These technical specifications are proposed, based on the needs and characteristics of HCMC. Moreover, gathering a database of possible parking solutions is an important prerequisite for the City Government as well as the research units to continue the next research in order to create a comprehensive solution that could help solving the problem of people's parking needs of HCMC.
\end{abstract}

Keywords: Mini-parking, Urban Transport Planning, Static Traffic Infrastructure, Ho Chi Minh City, Traffic System

\section{General Introduction}

Research background of current development status of concentrated parking system in Ho Chi Minh City Ho Chi Minh City is the urban area with the highest ratio of individual motor vehicles to the City population in Vietnam (personal motor vehicles account for $80 \%$ of the population). Moreover, Ho Chi Minh City has highest number of motor vehicles registered in the country with 7.6 million vehicles, 2016 [1]. Because the number of vehicles currently in circulation is very large and will increase rapidly in the near future, the transport infrastructure system is under increasing pressure, leading to an essential problem for the current traffic infrastructure system. The City Government must develop adequate transport infrastructure [3]. Among the city's static traffic infrastructure systems, the public parking system is one of the transportation infrastructures that are under the greatest pressure, especially in the central area [2].

To solve the problem of people's parking needs, since 2013, Ho Chi Minh City has tried to develop a system of public parking lots and stations in the city, through approving, announcing, calling for investment and implementing of concentrated parking projects both on the ground and underground parking in the central area. However, after many years, most of underground parking and concentrated parking projects have failed and stalled, making the parking management situation in the city center increasingly serious. From August 2018, the City Government has assigned the Department of Transport to deploy a pilot project of car parking systems on the road surface in 24 streets in three districts of District 1, 5 and 10 and then adjusted into 23 routes [4]. The pilot project is a remarkable turning point when the City Government has changed the view and direction of management, planning and development of on-street parking; instead of trying to remove the on-street parking lot, the City Government is on the way to formally planning and developing this model. However, after one year of implementation, due to the existence of many shortcomings and limitations in many stages (eg. management, technology, supporting infrastructure, etc.), the on-street car parking systems has not really reached its full potential as well as achieved the initial expectations of the authorities. More specifically, according to the results of the study [1] on "Understanding On-street Parking Management in 
Developing Megacity - A Case Study in Ho Chi Minh City" in 2019, although the On-street parking project provides more than 1000 parking slots, the actual amount of car parking is much lower than expected due to the ineffectiveness and lack of uniformnity in management, monitoring, sanctioning systems and appropriate pricing mechanism. In addition, the system of underground and multi-level car parks was approved according to the city's transport development planning approved by the Prime Minister since 2013 with a total of 8 projects with a total scale of $169,000 \mathrm{~m}^{2}$. However, so far, most of these projects are still on paper [5-7]. Thus, there were two groups of solutions on planning, developing and managing the parking system in Ho Chi Minh City area that failed to solve the problem of people's parking needs.

Although facing many difficulties, the parking demand in the downtown area is a certain problem that must be solved. Therefore, the Department of Planning and Architecture of Ho Chi Minh City cooperates with the Department of Transport to research and propose to pilot some multi-level car parks, before proceeding to apply to the city center.

\section{Criteria and Characteristics of Small-sized Parking Lots Are Proposed for Research}

The following are the characteristics of the parking models that will be applied as well as the criterias to approve locations where automatic parking can be built in accordance with the objectives of the proposed project.

\subsection{Characteristics of Small-sized, Automatic and Multi-Storey Car Parks}

Required small land occupation, can accommodate many vehicles, can be arranged flexibly in many different locations with not too large distance and service radius $(200-500 \mathrm{~m})$, suitable for parking conditions and needs in the inner city area;

Assembled by steel structure; therefore, the construction time is fast; construction can be dismantled / relocated / reused (depending on the stages that allow investment and exploitation). Not cause much impact on existing urban infrastructure and surrounding structures;

Managed by advanced technology, controlled by intelligent systems, so it does not affect the landscape and the environment; safety for users, isolated and closed fire prevention plan;

There are many solutions covering the surface to create a common aesthetic in urban space (glass, decorative images, advertising...), a diverse and flexible architectural form to combine or integrate with the surrounding landscape.

Construction scale is quite small, structure and design are depended on location and area of land lot, specifically as follows:

Area of land occupation: at least from $50 \mathrm{~m}^{2}$ to $70 \mathrm{~m}^{2}$ (depending on parking model); maximum area depends on combination module solutions;

Capacity: Approximately 6-200 cars (have not yet implemented an integrated layout in the parking lot using the automated car parking system, can only be arranged by other modules or combined in the construction of a multi-storey car park using steep ram);

Length: at least $7 \mathrm{~m}$; Width: at least $5.5 \mathrm{~m}$;

Height: at least $8 \mathrm{~m}$ (for floating structures, in multiple leveled);

Design: diverse, depend on integrated model and size of land lot;

Structure: assembled according to steel structure together with lifting / supporting / controlling system...;

Covered surface and decoration as required, ensure aesthetic, landscape.

Note: the backup generator layout to ensure safe operation in case of power failure. With a scale of more than 20 vehicles, an additional fire extinguishing system (and foam if necessary) is required.

\subsection{Criterias for Proposing Places for Automatic Parking}

1. Vacant land/setback space (area $50-500 \mathrm{~m}^{2}$ ) or existing parking included in area of public spaces/public buildings, such as: parking, stadium, cultural center, shopping mall, recreation center, wedding center, residential area or departments, hotel, university, hospital, etc. Depend on characteristics of each location, different modules are proposed and applied flexibly;

2. Private lands (not yet built houses, constructions, etc.), projects which have not been implemented yet, or are requested to change their functions to apply for permission to temporarily build auto parking lots (considered depending on the scale and stage of investment permission);

3. Must be adjacent, connected to existing road widths of at least $6 \mathrm{~m}$ wide;

4. There is a system of convenient transport infrastructure, ensuring motorized vehicles, including fire protection vehicles to circulate smoothly, safely and quickly; ensure safety, not cause traffic jams or negatively impact on regional traffic;

5. Ensuring the safety conditions, fire prevention and fighting;

6. Not within the elementary school premises or where there are many pedestrians crossing the driveway.

\subsection{Related Legal Documents and Technical Code}

Based on requirements and criterias of proposed solutions, there are guidances, resolutions and national codes in Vietnam:

1. Law on Planning (regarding to urban transport development) [8];

2. Law on Construction (regarding to underground parking and multi-level parking) [9];

3. Law on Road Traffic [10];

4. Law on Inland Waterway Transport (regarding station and floating facilities) [11];

5. National Building Code [12]; 
6. National Technical Regulation on Rule of Inland- water way Ships Classification and Construction (regarding the steel structure of floating vehicles) [13].

\section{Some Initial Surveys for Medium- and Small-sized Parking Modules}

In this section, some feasible options, which have been applied to countries and regions, are presented.

\subsection{Feasible Models for Residential Housing}

- 2-level garage model for residential housing with 2 pillars or 4 pillars (Figures 1 and 2):
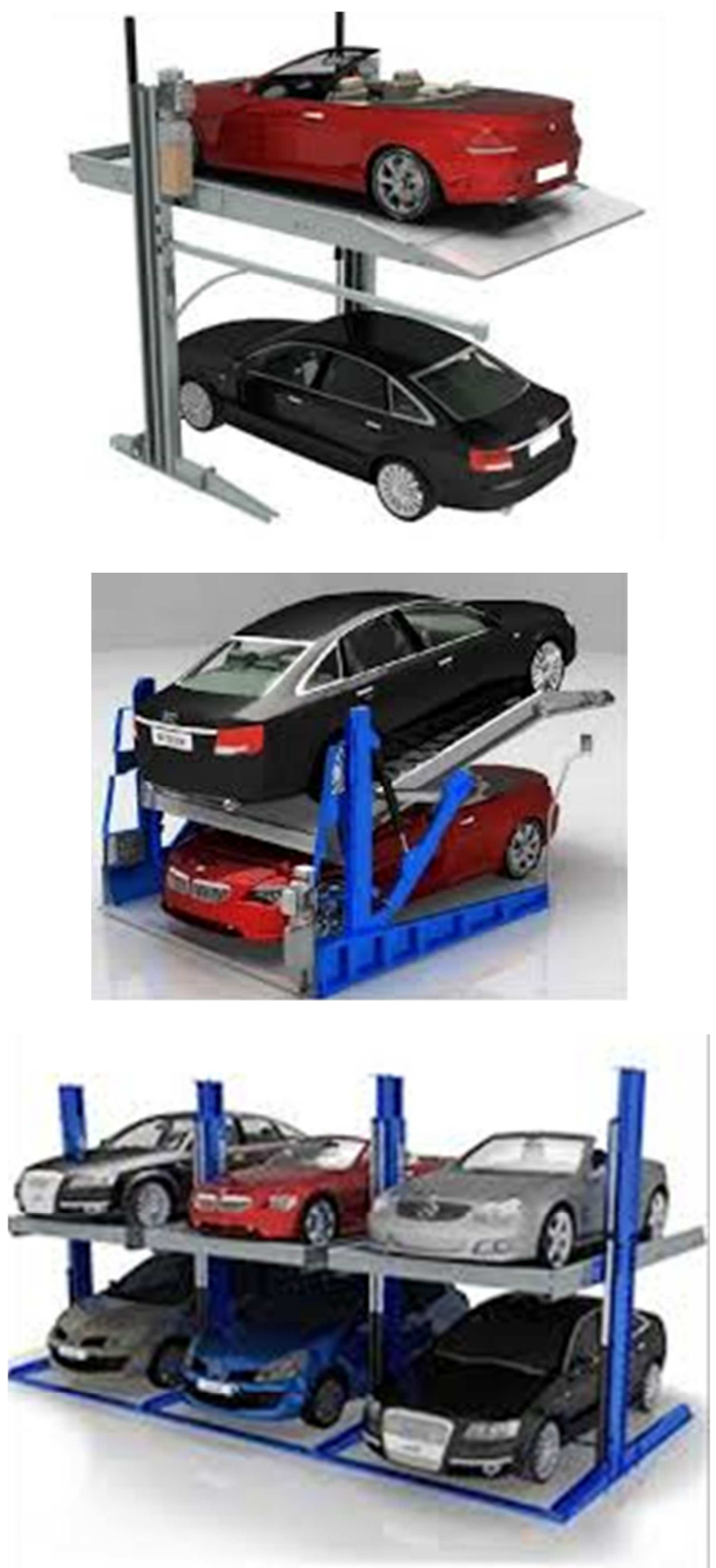

Figure 1. Residental multi-level garage models with 2 pillars.

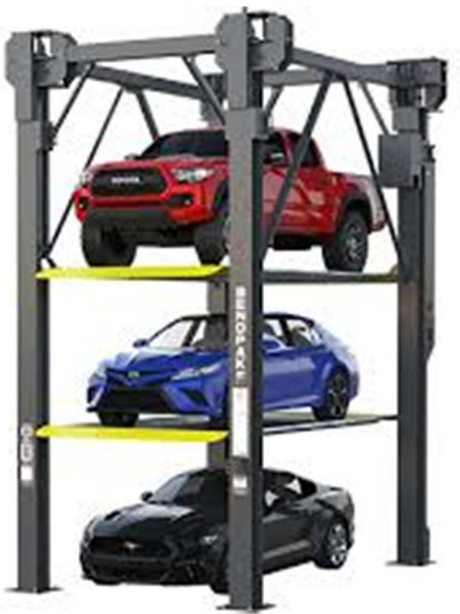

Figure 2. Residental multi-level garage models with 4 pillars.

- Models of shared space car garage (Figure 3):

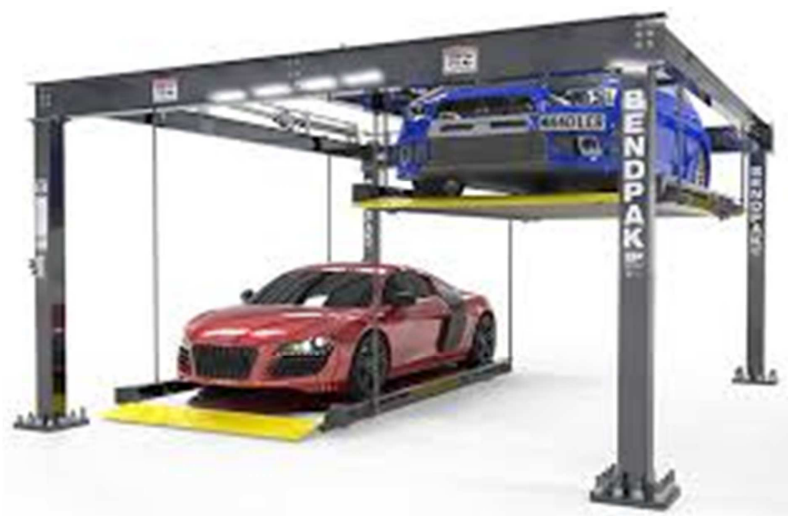

Figure 3. Multi-level garage models with shared space.

\subsection{On-Street Car Parking Modules on a Multi-level Assembly Structure}

Quick assembled structures in building setback or between building blocks. For example, the figure 4 shows the multiple level stack parking lot in the Broadway District, New York City [14].

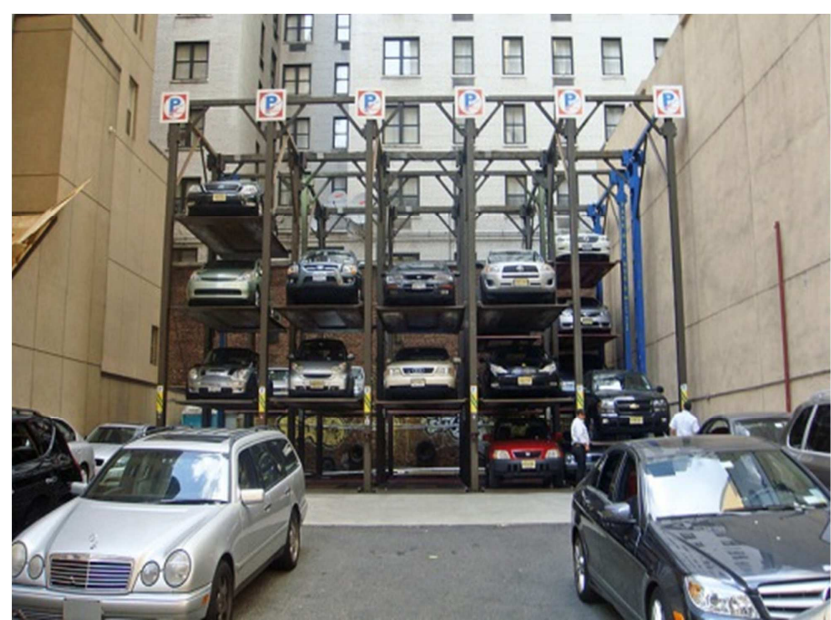

Figure 4. Multiple level stack parking lot in the Broadway District, New York City [14]. 


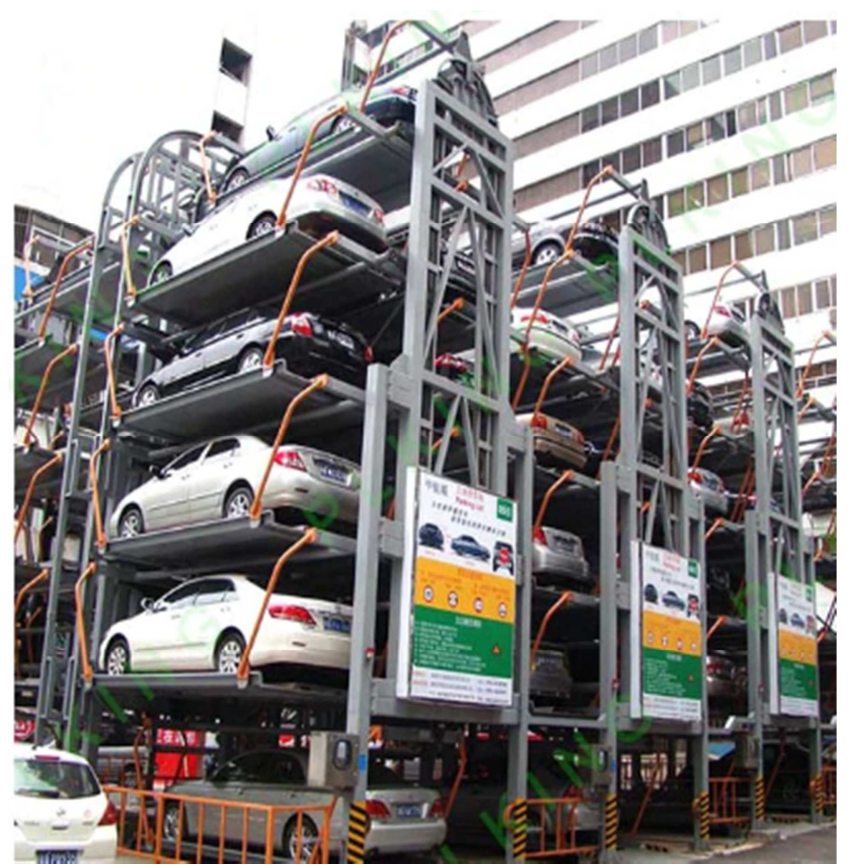

Figure 5. Model of vertical rotary structure.

Model of vertical conveyor structures, manufactured by China and India, have been exported to many countries. (Figure 5). The features of these approaches are as follows [15, 16]:

1. Flexible, vertical cycle series parking system covers sall area, flexible, and can be set up independently, also can be attached into building, also can be more than one combination, small vertical cycle series parking equipment can be installed in the living area, beside the building, save the land space;

2. Rapidly, parking car and taking car out in short time;

3. Economically, build vertical type parking system can save the considerable cost of purchasing land, conductive to the rational planning and optimize the design, improve the comprehensive economic benefit;

4. Save electric power, vertical circulating mechanical parking system typically does not require forced ventilation, no large-area lighting, power consumption only $35 \%$ of the common underground parking garage.

These parking systems have such advantages as [15]:

1. Less land occupation, large capacity, high density parking;

2. Single garage could be disposed multi-entrances to improve the using efficiency and relieve congestion at the peak period;

3. Automatically revolving and U-turn while parking and picking out for users convenience;

4. Full use of spaces and flexible building garage according to area and users' request;

5. Flexible structures as the whole ground structure or half underground structure, steel structure or concrete structure;

6. High efficiency and fast speed: realized multi-user's parking and picking at the same time.
However, parking models of 2- or 3-level sliding system (as in figure 6) do not look too complicated, have a compact structure and are convenient for layout even in the basements of apartment buildings.

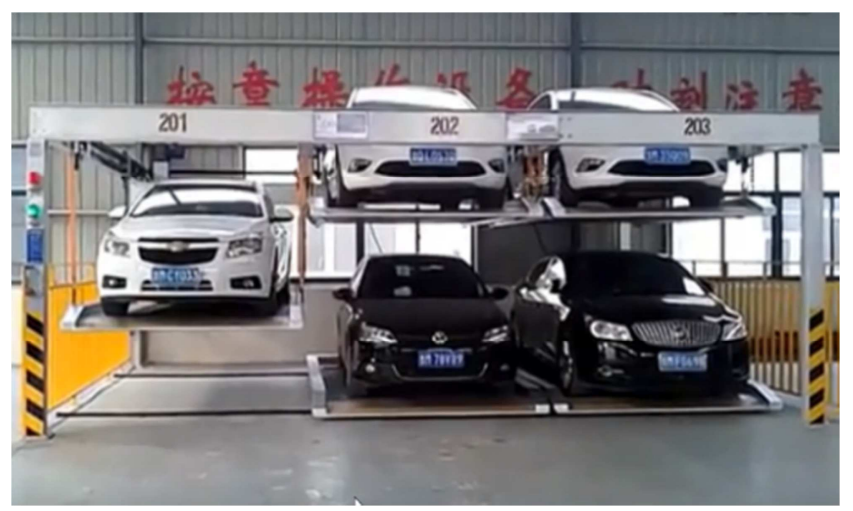

Figure 6. Model of 2 level parking with horizontal sliding system. (https://www.youtube.com/watch? $v=l \_d W z F 7 q U V Y$ ).

\subsection{Hybridization Models}

Because of Ho Chi Minh City characteristic, it is also possible to consider the following hybridization modules:

Models based on river ferries (pontons) but anchored... will be designed according to current inland ship construction rules, codes and regulations e.g. $[11,12]$;

2-level garage models where ground level for cars and upper levels with lighter structure for motorbikes (figure 7).

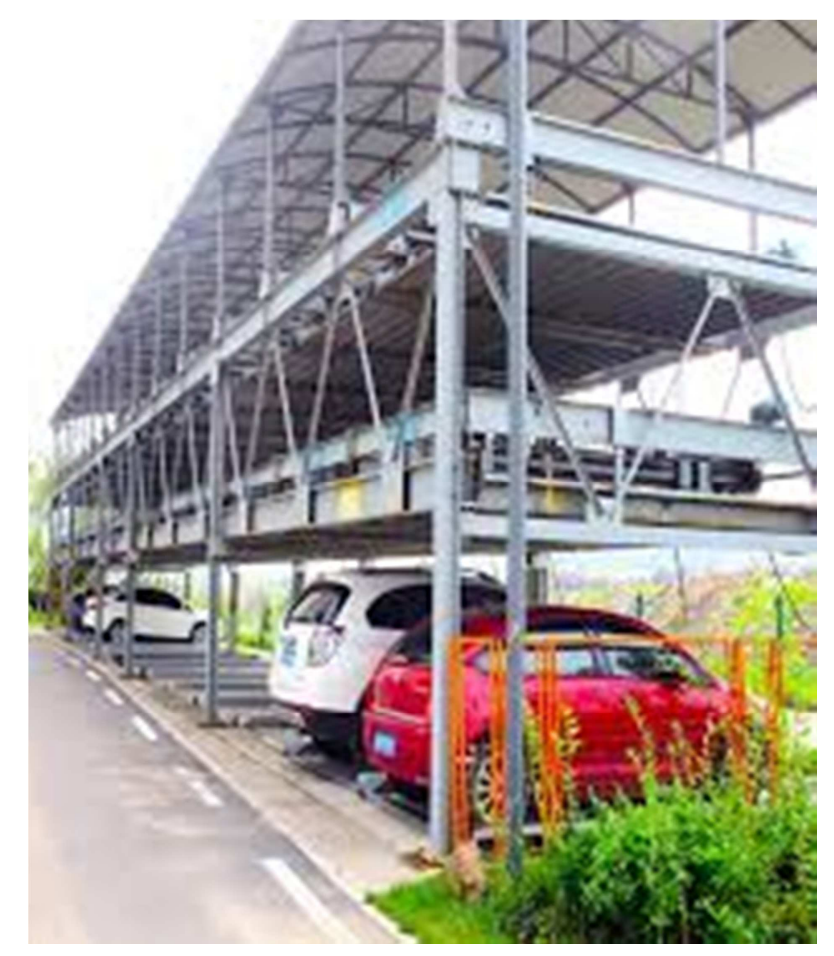

Figure 7. Prefabricated steel building structure for cars and motobikes parking [16].

\section{Conclusions}

The models and solutions for parking are synthesized, 
analyzed and proposed by the research team to solve the current problem of meeting the parking needs of the people of Ho Chi Minh City, especially in the downtown area or important transportation hubs of the region.

Based on the characteristics of the study area (bare land fund for infrastructure development is very limited, relatively complete technical infrastructure, high land value, etc.), the technical characteristics of the parking solutions and the criterias of possible deployment areas are proposed. Then models - technical solutions have been specifically proposed, clearly illustrated as well as cases that have been successfully applied in the world. Based on the aggregated results, the authorities or research organizations that are interested in traffic planning as well as the development of parking systems can make reference data to advance to the next steps (research - needs analysis, environmental impact assessment, feasibility assessment, etc.) in order to effectively and successfully address the issue of meeting the needs of parking for people.

\section{References}

[1] Vo Minh Phuc (2019), Understanding On-street Parking Management in Developing Megacity - A Case Study in Ho Chi Minh City, MSc thesis, TU Darmstadt, 2019.

[2] Vo Minh Phuc, Vo Trong Cang (2019), “On-street Parking Management Toward Effective Transport System in Central Area of Megacity, Case Study in Ho Chi Minh City", Proc. International Conference on Logistics and Industrial Engineering, ICLIE 2019, Aug 25 2019, HCM city - Việt Nam.

[3] Truong Thi My Thanh (2017), Parking Management Strategies for Asian Developing Countries, PhD thesis, TU Darmstadt.

[4] Resolution No. 01/2018/NQ-HĐND of Ho Chi Minh City
People's Council on Issuing the fee level for temporarily using road bed to park cars in Ho Chi Minh City City, March 16, 2018.

[5] Decision No. 206/2004/QĐ-TTg of the Prime Minister on the Vietnam Transport Development Strategy to 2020, December $10,2004$.

[6] Decision No. 24/2010/ QĐ-TTg of the Prime Minister on approving the adjusted General Planning on construction of Ho Chi Minh City up to 2025, Jan 6, 2010.

[7] Decision No. 568/2013/QĐ-TTg of the Prime Minister on approving the adjusted adjusted the development planning of Ho Chi Minh City Transport to 2020, vision after 2020, April 8, 2013.

[8] Law on Planning (30/2009/QH12), June 17, 2009.

[9] Law on Construction (50/2014/QH13), June 18, 2014.

[10] Law on Road Traffic (23/2008/QH12), Nov 13, 2008.

[11] Law on Inland Waterway Traffic (48/2014/QH13).

[12] National Technical Regulation on Rule of Inland - waterway Ships Classification and Construction (QCVN 72: 2013/BGTVT).

[13] National Technical Construction Planning Code (QCVN 01: 2019/BXD), July 31, 2019.

[14] https://commons.wikimedia.org/wiki/File:Multi-level_stack_p arking_NYC_07_2010_9583.JPG.

[15] Automatic Vertical Rotary Parking System http://www.autoparkingmachine.com/sdp/2326505/4/cp-7382 384/0/Vertical_Rotary_parking.html.

[16] https://www.exportersindia.com/indian-suppliers/hydraulic-car -parking-system.htm. 